\title{
Prevalence of Parkinson Disease in Hospitalized Patients With Congestive Heart Failure
}

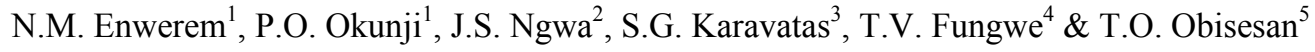 \\ ${ }^{1}$ Division of Nursing, College of Nursing and Allied Health Sciences, Howard University, USA \\ ${ }^{2}$ Division of Cardiovascular Medicine, College of Medicine, Howard University, USA \\ ${ }^{3}$ Department of Physical Therapy, College of Nursing and Allied Health Sciences, Howard University, USA \\ ${ }^{4}$ Department of Nutritional Sciences, College of Nursing and Allied Health Sciences, Howard University, USA \\ ${ }^{5}$ Division of Geriatrics, Department of Medicine and Clinical/Translational Science Program, Howard \\ University Hospital, USA \\ Correspondence: N.M. Enwerem, Division of Nursing, College of Nursing and Allied Health Sciences, Howard \\ University, USA.
}

Received: March 28, 2018

Accepted: April 18, 2018

Online Published: April 23, 2018

doi:10.20849/ijsn.v3i2.371

URL: https://doi.org/10.20849/ijsn.v3i2.371

\begin{abstract}
Background: Parkinson's disease (PD) is the second most common neurodegenerative disease, after Alzheimer's disease, affecting approximately one million persons aged 65 years and above in the United States. Parkinson's disease represents a major medical concern for health professionals, national healthcare bodies and a heavy burden for caregivers. Heart failure occurred twice as frequently in elderly PD patients as in non-PD patients. There is paucity of information on the association of patient and hospital characteristics on the outcomes of inpatient with both congestive heart failure and Parkinson disease.

Congestive Heart Failure with PD as a comorbidity will increase the cost of care and health resources. We investigate on the current prevalence and factors that affect the inpatient with both CHF and PD conditions using a longitudinal datasets from National Inpatient Samples. The results obtained from this study will provide information that will reduce frequent readmission, length of stay, total charges and mortality rate in this population.

Methods: Data from the National Inpatient Samples (NIS) were extracted and analyzed using ICD 9 codes (CHF 428 , PD 332) for the main diagnosis. For continuous variables, we calculated the mean and standard deviations and evaluated significant differences of these factors by Parkinson disease status using the t-test. For categorical variables, we obtained the counts (proportions) and evaluated significant differences using the Chi-square and Fisher's exact test Propensity score was utilized to match age, gender and race using logistic model for hospital death and generalized linear model for length of stay (LOS) and hospital charges.

Result: The overall frequency of Parkinson disease (PD) in congestive heart failure was $1.54 \%(\mathrm{n}=10,748)$. PD patients with CHF were more likely to be males (53.13\%; 5462) and Caucasians $(82.24 \%$; $n=8454)$. The average age of inpatient was approximately 80 years $(\mathrm{SD}=8.05)$. Hospital admission, decreases with median household income. Patients with low income $(\$ 1$ - \$38,999) were admitted more with $3002(29.70 \%)$ than those with higher income $(\$ 63,000$ and more) with $2230(22.06 \%)$. Length of stay (LOS) $(\mathrm{p}<0.0001)$ and total charge incurred during hospitalization were less in patients with PD $(\mathrm{p}<0.005)$ (table 1). In these analyses, we found that patients with PD were discharged more from urban non-teaching hospital than urban teaching hospital $(\mathrm{p}<0.0001)$.

Conclusion: The general characteristics and frequency of the participant in this study are summarized in Table I. Accordingly, characteristics of patients with congestive heart failure with or without Parkinson's disease did not differ by age, gender, or ethnicity $(\mathrm{P}>1.000)$. Similarly, hospital death rates $(\%)$ were not different $(\mathrm{P}>1.000)$, although hospital length of stay $(\mathrm{P}<1.000)$ and total charge incurred during hospitalization were less in patients with PD $(\mathrm{p}<0.005)$
\end{abstract}

Keywords: Parkinson disease, congestive heart failure, national inpatient sample, health outcomes 


\section{Introduction}

Parkinson's disease (PD) is the second most common neurodegenerative disease, after Alzheimer's disease (AD), affecting approximately one million persons aged 65 years and above in the United States (Chen et al, 2007). Parkinson's disease represents a major medical concern for health professionals, national healthcare bodies and a heavy burden for caregivers (Nance, 2015 and Cruickshank et al., 2015). It greatly affects the quality of life of patients (Zhang et al., 2016). Incidence of PD disease is approximately 1.8 times higher in men versus women (1.5-2.0) (Hirtz et al. 2007; Mhyre, et al., 2012). The study of Zhang et al, 2016 revealed that the incidence of PD is slightly higher in males than in females; the ratio was close to $1: 1$, the average age of PD patients was about 60 years, the education level of patients with PD was paralleled with that of age-matched (40-70 years old) (Ransmayr, 2015), and education is not an associated factor for PD. The socioeconomic burden of PD is great with estimates of both direct and indirect costs upward of about \$23 billion every year in the US (Huse et al. 2005; Mhyre, et al., 2012). Age is the single greatest risk factor for PD with the number of world-wide cases increasing from an estimated 4.1 million (340,000 US cases) in 2005 to nearly 8.7 million (610,000 US cases) by 2030 (Dorsey et al. 2007; Mhyre, et al., 2012). Whites have a substantially higher prevalence and incidence of Parkinson disease than Blacks or Asians (Willis et al., 2010). The incidence and prevalence of Parkinson disease varied significantly across the United States (see fig 1, Willis et al., 2010). Disease rates were highest in the Midwest and Northeast regions, where the incidence and prevalence of PD were 2-10 times greater than the rates of many Western and Southern US counties (Willis et al., 2010). Parkinson disease prevalence for the most urban counties was significantly greater than that for the most rural counties. Similarly, PD incidence for the most urban counties was significantly greater than that for the most rural counties (Willis et al., 2010).

Parkinson Disease, is characterized by four major motor symptoms (MS) including resting tremor, bradykinesia, rigidity, and postural and gait instability, and numerous nonmotor symptoms (NMS), such as neuropsychiatric symptoms, sleep disorders, autonomic dysfunctions, and sensory disturbances (Zhang et al., 2016). Autonomic dysfunctions include the deregulations of sweat gland, body temperature, cardiovascular, gastrointestinal, and genitourinary systems, mainly relevant to appearance of Lewy bodies in sympathetic or parasympathetic cholinergic ganglion, and sympathetic adrenergic nerve ganglion. The Autonomic disorder, leads to major problems such as constipation, frequent urination at night, orthostatic hypotension, fatigue, polyhidrosis, and sexual dysfunction (Truong et al., 2008; Zhang et al., 2016).

Individuals with PD are also likely to suffer from a variety of other chronic diseases as a result of the disease process or medication management (Csoti et al., 2016). In various studies on comorbidity, up to $80 \%$ of the patients had five or more concomitant diseases (Gorell et al. 1994; Leibson et al. 2006; Csoti et al., 2016). Comorbidity related to disease process include; diabetes mellitus (Miyake et al. 2010; Xu et al. 2011; Sun et al. 2012), dyslipidemia (Firoz et al. 2015); obesity (Hu et al. 2006); arterial hypertension(Pagano et al. 2014); Gastritis and gastroesophageal reflux (Maeda et al. 2013); In a cross-sectional study of a national Medicare database, heart failure occurred twice as frequently in elderly PD patients as in non-PD patients (Zesiewicz et al., 2004). People living with PD are twice as likely as the general population to develop Cardiac disease (CD), and they have a $50 \%$ greater chance of dying from it. Recent research suggests that people with PD who have a high or medium risk of $\mathrm{CD}$ tend to have more problems with walking and memory. While both $\mathrm{CD}$ and PD become more common with age, people with poorer cardiovascular health also have worse walking and memory problems, even in the early stages of PD, suggesting that assessment and treatment of vascular health may help improve these patients' PD symptoms as well( Parkinson's UK, 2016, Swallow et al.,2016 ). There is paucity of information on the association of patient and hospital characteristics on the outcomes of inpatient with both congestive heart failure and Parkinson disease. CHF with PD as comorbidity will increase the cost of care and health resources. The goal of this study is to determine the prevalence of CHF and PD, contributing factors including the costs of hospital stays in a National Inpatient Sample. The results obtained from this study will provide information that will reduce frequent readmission, length of stay, total charges and mortality rate in this population.

\section{Research Designs and Method}

This study is a secondary analysis that utilizes data from the HCUP Nationwide Inpatient Sample (NIS). The HCUP manages the health care datasets and related software tools and products developed through a Federal-State-Industry partnership and sponsored by the Agency for Healthcare Research and Quality (AHQR). HCUP aggregates the data collection efforts of State data organizations hospital associations, private data organizations and the Federal government to create a national information resource of patient-level health care data (HCUP Partners) > HCUP includes acute care hospital data in the United States, with all-payer (source of payment for the hospital length of stay). 


\subsection{Study Population}

In this study, data of patients with CHF were selected from the 2012 hospital discharge information according to hospital and patients' characteristics such as age, gender, race insurance, family median income, comorbidities, hospital location and teaching status and hospital charge. This range was selected due to data availability. Selection of samples was aided by the exiting NIS database and ICD-9-CM.

\subsection{Inclusion and Exclusion Criteria}

The NIS data samples were selected and extracted on the basis of the following criteria: (a) inpatient diagnosed with CHF and related comorbidities (b) inpatient admitted to nonfederal hospitals, (c) age 55 years and above. The exclusions were (a) pediatric inpatients and age below 55 years and above. The exclusions were (a) pediatric inpatients and age below 55 years (b) discharges from federal and government hospitals.

\subsection{Patient Measures}

Measures were as follows: Age (55 years and above); gender (male, female); race (white, black, others); income (\$1,000 - 38,999; \$39,000-\$47,999; \$48,000-\$62,999; \$63,000 and above); insurance (Medicare, Medicaid, private including HMO, Others); primary diagnosis (CHF and Parkinson disease); comorbidities (diabetes, stoke, obstructive sleep apnea, morbid obesity, renal insufficiency); hospital characteristics ( rural, urban non-teaching, urban-teaching).

\subsection{Statistical Analysis}

Descriptive statistics were computed to assess baseline clinical and demographic factors associated with PD among participants with CHF. For continuous variables, mean and standard deviations and evaluated significant differences of these factors by Parkinson Disease status were analyzed using the t-test. For categorical variables the counts (proportions) were obtained and evaluated for significant differences using the Chi-square and Fisher's exact test (table 1). The relationship between primary outcomes (Hospital charges, Length of Stay, Mortality Rates) and Parkinson Disease status were evaluated using multiple regression analysis. Propensity score was utilized to match participants with age, gender and race using logistic model for hospital death and generalized linear model for LOS and hospital charges. Univariate analysis was performed to assess potential confounders for the association between PD status and the outcome measures. The factors that were significantly associated with the primary outcome measures and PD status (primary independent) was included in the multivariate stepwise regression analysis (table 2). An interaction test and graphical plots were performed to assess the association between and diabetes and PD status with the outcome measures. P-value less than 0.05 were considered statistically significant and confidence intervals (CI) were calculated at the $95 \%$ level (Table 3). Data analysis was conducted using the statistical analysis system (SAS) software 9.3 (SAS Institute, Cary. NC) and statistical Analysis and Graphics (NCSS 9.07, Kaysville, UT) (Statistical Analysis System -SAS).

\section{Results}

The general characteristics and frequency of the participant in this study are summarized in Table I.

The overall frequency of Parkinson disease (PD) in congestive heart failure was $1.54 \%(\mathrm{n}=10,748)$. PD patients with CHF were more likely to be males (53.13\%; 5462) and Caucasians $(82.24 \%$; $n=8454)$. The average age of inpatient was approximately 80 years $(\mathrm{SD}=8.05)$. Hospital admission, decreased with median household income. Patients with low income $(\$ 1$ - \$38,999) were admitted more with $3002(29.70 \%)$ than those with higher income $(\$ 63,000$ and more) with $2230(22.06 \%)$. Length of stay (LOS) $(\mathrm{p}<0.0001)$ and total charge incurred during hospitalization were less in patients with PD $(\mathrm{p}<0.005)$ (table 1). The discharge rate of patients with PD was more from urban non-teaching hospital than urban teaching hospital $(\mathrm{p}<0.0001)$

\subsection{Co-morbid Disorders in PD by CHF Diagnosis}

Renal Insufficiency (3.30\%), diabetes (27.85\%), morbid obesity and obstructive sleep apnea were higher for inpatient without PD. Stroke was more prevalent in patient with PD. These differences were not significant except for morbid obesity which was significantly less common in patients with $\mathrm{PD}(\mathrm{p}<0.024$ (table 1).

\subsection{Mortality Rate, Length of Stay and Total Charge}

These results showed differences between patient with PD and those without in both adjusted and unadjusted analysis of the outcomes when matched with age, gender and race as shown in table 2. Logistic analysis for hospital death showed Odds $(0.994, p>0.917)$ for unadjusted and Odds $(0.996, p=0.940)$ for adjusted. For LOS unadjusted analysis showed Beta $(0.189, \mathrm{p}<0.011)$ and adjusted Beta $(0.225, \mathrm{p}<0.003)$. While hospital charge showed Beta $(-4247, \mathrm{p}<0.0001)$ and adjusted Beta $(-3899.51, \mathrm{p}<0.0001)$ 


\subsection{Patient and Hospital Characteristics by Outcomes}

Age and gender significantly affected hospital death and total charge $(p<0.0001)$. Gender did not affect length of stay $(p=0.283)$. Hospital charge, was affected by patients with high income $\$ 63000$ and more $(p<0.0 .0001)$. Diabetes and stroke, significantly affected total charge $(p<0.0001)$. Diabetes, stroke and morbidity significantly affected length of stay. Stroke significantly affected hospital death $(p<0.0001)$. Obstructive sleep apnea, significantly affected hospital death $(\mathrm{p}<0.001)$.

Table 1. General characteristics of patients with congestive heart failure with or without Parkinson's disease

\begin{tabular}{|c|c|c|c|}
\hline Characteristics & $\begin{array}{c}\text { Parkinson } \\
(\mathrm{N}=\mathbf{1 0 , 7 4 8 )}\end{array}$ & $\begin{array}{c}\text { No Parkinson } \\
(N=\mathbf{2 0 5 6 0 )}\end{array}$ & P value \\
\hline Age - yrs. & $79.79(8.05)$ & $79.78(8.05)$ & 1.000 \\
\hline \multicolumn{4}{|l|}{ Gender (\%) } \\
\hline Male & $5462(53.13 \%)$ & $10924(53.13 \%)$ & 1.000 \\
\hline Female & $4818(46.87)$ & $9636(46.87)$ & \\
\hline \multicolumn{4}{|l|}{ Race (\%) } \\
\hline White (1) & $8454(82.24 \%)$ & $16,908(82.24 \%)$ & 1.000 \\
\hline Black (2) & $783(7.62 \%)$ & $1566(7.62 \%)$ & \\
\hline Hispanics (3) & $617(6.00 \%)$ & $1234(6.00 \%)$ & \\
\hline Asian or Pacific Islander (4) & $165(1.61 \%)$ & $330(1.61 \%)$ & \\
\hline Native Americans (5) & $34(0.33 \%)$ & $68(0.33 \%)$ & \\
\hline Others (6) & $227(2.21 \%)$ & $454(2.21 \%)$ & \\
\hline \multicolumn{4}{|l|}{ Hospital Death (\%) } \\
\hline Yes & $568(5.53 \%)$ & $1142(5.56 \%)$ & 0.917 \\
\hline No & $9709(94.47 \%)$ & $19,413(94.44 \%)$ & \\
\hline Length of Stay (IQR) & $6.22(3.00,8.00)$ & $6.04(3.00,7.00)$ & $<.0001$ \\
\hline Total Charge (IQR) & $45,501(15,438,52,044)$ & $49,748(15,266,56,179)$ & 0.005 \\
\hline \multicolumn{4}{|l|}{ Median Household Income (\%) } \\
\hline $1(\$ 1-\$ 38,999)$ & $3002(29.70 \%)$ & $6043(29.92 \%)$ & 0.234 \\
\hline $2(\$ 39,000-\$ 47,999)$ & $2508(24.81 \%)$ & $5195(25.72 \%)$ & \\
\hline $3(\$ 48,000-\$ 62,999)$ & $2368(23.43 \%)$ & $4607(22.81 \%)$ & \\
\hline $4(\$ 63,000$ or More $)$ & $2230(22.06 \%)$ & $4350(21.54 \%)$ & \\
\hline Renal Insufficiency (\%) & $339(3.30 \%)$ & $736(3.58 \%)$ & 0.203 \\
\hline Diabetes (\%) & $2863(27.85 \%)$ & $5846(28.43 \%)$ & 0.283 \\
\hline Stroke (\%) & $169(1.64 \%)$ & $304(1.48 \%)$ & 0.265 \\
\hline Morbid Obesity (\%) & $457(4.45 \%)$ & $1034(5.03 \%)$ & 0.024 \\
\hline Obstructive Sleep Apnea (\%) & $806(7.84 \%)$ & $1681(8.18 \%)$ & 0.308 \\
\hline \multicolumn{4}{|l|}{ Hospital Characteristics } \\
\hline Rural (1) & $1676(16.30 \%)$ & $2983(14.15 \%)$ & $<.0001$ \\
\hline Urban Non-Teaching (2) & $4385(42.66 \%)$ & $8522(41.45 \%)$ & \\
\hline Urban Teaching (3) & $4219(41.04 \%)$ & $9055(44.04 \%)$ & \\
\hline
\end{tabular}

Values are Mean (SD) for Continuous Variables and Count (\%) for Categorical Variables.

For normally distributed variables $p$ values were computed with t-tests; Wilcoxon Rank-sum Test for non-normally distributed. Chi-square test for Categorical Variables.

$\mathrm{PD}=$ Parkinson's Disease; Participants are matched by Age, Gender and Race. 
Table 2. Hospital death, length of stay and total charge for congestive heart failure patients with and without Parkinson's disease

\begin{tabular}{|c|c|c|c|c|c|c|c|c|}
\hline \multirow{4}{*}{$\begin{array}{c}\text { Logistic Model } \\
\text { Hospital Death }\end{array}$} & \multicolumn{8}{|c|}{ Parkinson' Disease Status (PD vs. No PD) } \\
\hline & \multicolumn{4}{|c|}{ Unadjusted Analysis } & \multicolumn{4}{|c|}{ Adjusted Analysis } \\
\hline & Odds & & & $\mathbf{P}$ & Odds & & & $\mathbf{P}$ \\
\hline & 0.994 & 0.897 & 1.103 & 0.917 & 0.996 & 0.897 & 1.106 & 0.940 \\
\hline GLM Model & Beta & SE & $\mathbf{T}$ & $\mathbf{P}$ & Beta & SE & $\mathbf{T}$ & $\mathbf{P}$ \\
\hline Length of Stay & 0.189 & 0.074 & 2.550 & 0.011 & 0.225 & 0.074 & 3.020 & 0.003 \\
\hline Total Charge & -4247.44 & 881.55 & -4.820 & $<0.0001$ & -3899.51 & 870.45 & -4.480 & $<0.0001$ \\
\hline
\end{tabular}

Unadjusted and Adjusted Association of Outcomes and Parkinson's Disease Status

Hospital Death: Model = Logistic Regression Analysis; Odds, 95\% Confidence Interval; P-values

Length of Stay and Total Charge: Model = Generalized Linear Model; Estimate, Standard Error, T-value, P-value

PD = Parkinson's Disease; Participants are matched by Age, Gender and Race;

Table 3. Logistic Regression Analysis of characteristics of patients based on Hospital Death, Length of Stay and Total Charge

\begin{tabular}{|c|c|c|c|c|c|c|c|c|c|c|}
\hline \multirow{3}{*}{$\begin{array}{l}\text { Characteristics } \\
\text { Age - yrs. }\end{array}$} & \multicolumn{4}{|c|}{ Hospital Death } & \multicolumn{3}{|c|}{ Length of Stay } & \multicolumn{3}{|c|}{ Total Charge } \\
\hline & Odds & $95 \%$ & C.I. & $\mathbf{P}$ & Beta & SE & $\mathbf{P}$ & Beta & SE & $\mathbf{P}$ \\
\hline & 1.028 & 1.020 & 1.035 & $<.0001$ & -0.018 & 0.005 & $<.0001$ & -685.420 & 53.504 & $<.0001$ \\
\hline Gender (Female vs. Male) & 0.830 & 0.751 & 0.917 & $<.0001$ & -0.076 & 0.071 & 0.283 & -4363.342 & 827.640 & $<.0001$ \\
\hline \multicolumn{11}{|l|}{ Race } \\
\hline Whites vs. Blacks & 0.973 & 0.800 & 1.185 & 0.719 & -0.247 & 0.137 & 0.071 & -559.290 & 1608.965 & 0.728 \\
\hline Hispanics vs. Blacks & 1.025 & 0.780 & 1.347 & 0.504 & 0.023 & 0.193 & 0.904 & 20517.087 & 2264.551 & $<.0001$ \\
\hline Asians vs. Blacks & 1.415 & 0.971 & 2.063 & 0.017 & 0.091 & 0.308 & 0.767 & 20690.417 & 3671.160 & $<.0001$ \\
\hline $\begin{array}{l}\text { Native Americans vs. } \\
\text { Blacks }\end{array}$ & 0.557 & 0.174 & 1.787 & 0.292 & -0.405 & 0.634 & 0.523 & -4473.239 & 7397.817 & 0.545 \\
\hline Others vs. Blacks & 0.850 & 0.571 & 1.266 & 0.602 & 0.642 & 0.271 & 0.018 & 12636.182 & 3154.094 & $<.0001$ \\
\hline Median Household Income & & & & & & & & & & \\
\hline $1(\$ 1-\$ 38,999)$ & ref & ref & ref & ref & ref & ref & ref & ref & ref & ref \\
\hline $2(\$ 39,000-\$ 47,999)$ & 0.975 & 0.848 & 1.121 & 0.245 & -0.088 & 0.097 & 0.362 & 359.937 & 1128.688 & 0.750 \\
\hline$-\$ 62,999)$ & 1.053 & 0.911 & 1.217 & 0.583 & -0.217 & 0.103 & 0.034 & 2535.418 & 1198.146 & 0.034 \\
\hline $4(\$ 63,000$ or More) & 1.083 & 0.934 & 1.256 & 0.247 & -0.049 & 0.106 & 0.642 & 10478.002 & 1244.842 & $<.0001$ \\
\hline Renal Inst & 0.960 & 0.732 & 1.26 & 0.772 & -0.373 & 0.191 & 0.051 & -1023.694 & 2227.501 & 0.646 \\
\hline Diabetes & 0.927 & 0.828 & 1.039 & 0.194 & -0.472 & 0.079 & $<.0001$ & -4454.506 & 916.142 & $<.0001$ \\
\hline Stroke & 1.861 & 1.366 & 2.535 & $<.0001$ & 1.464 & 0.285 & $<.0001$ & 18855.438 & 3315.552 & $<.0001$ \\
\hline Morbid Obesity & 0.970 & 0.728 & 1.291 & 0.834 & 0.709 & 0.173 & $<.0001$ & 5655.796 & 2029.571 & 0.005 \\
\hline Obstructive Sleep Apnea & 0.660 & 0.522 & 0.834 & 0.001 & 0.021 & 0.135 & 0.877 & 289.416 & 1580.117 & 0.855 \\
\hline $\begin{array}{l}\text { Urban Non-Teaching vs. } \\
\text { Rural }\end{array}$ & 0.974 & 0.830 & 1.144 & 0.497 & 0.862 & 0.113 & $<.0001$ & 22560.453 & 1307.922 & $<.0001$ \\
\hline Urban Teaching vs. Rural & 1.025 & 0.874 & 1.202 & 0.501 & 1.394 & 0.112 & $<.0001$ & 23730.412 & 1304.881 & $<.0001$ \\
\hline
\end{tabular}

Hospital Death: Model = Logistic Regression Analysis; Odds, 95\% Confidence Interval; P-values

Length of Stay and Total Charge: Model $=$ Generalized Linear Regression Model; Estimate, Standard Error,

T-value, P-value

PD = Parkinson's Disease; Participants are matched by Age, Gender and Race; ref = reference group 


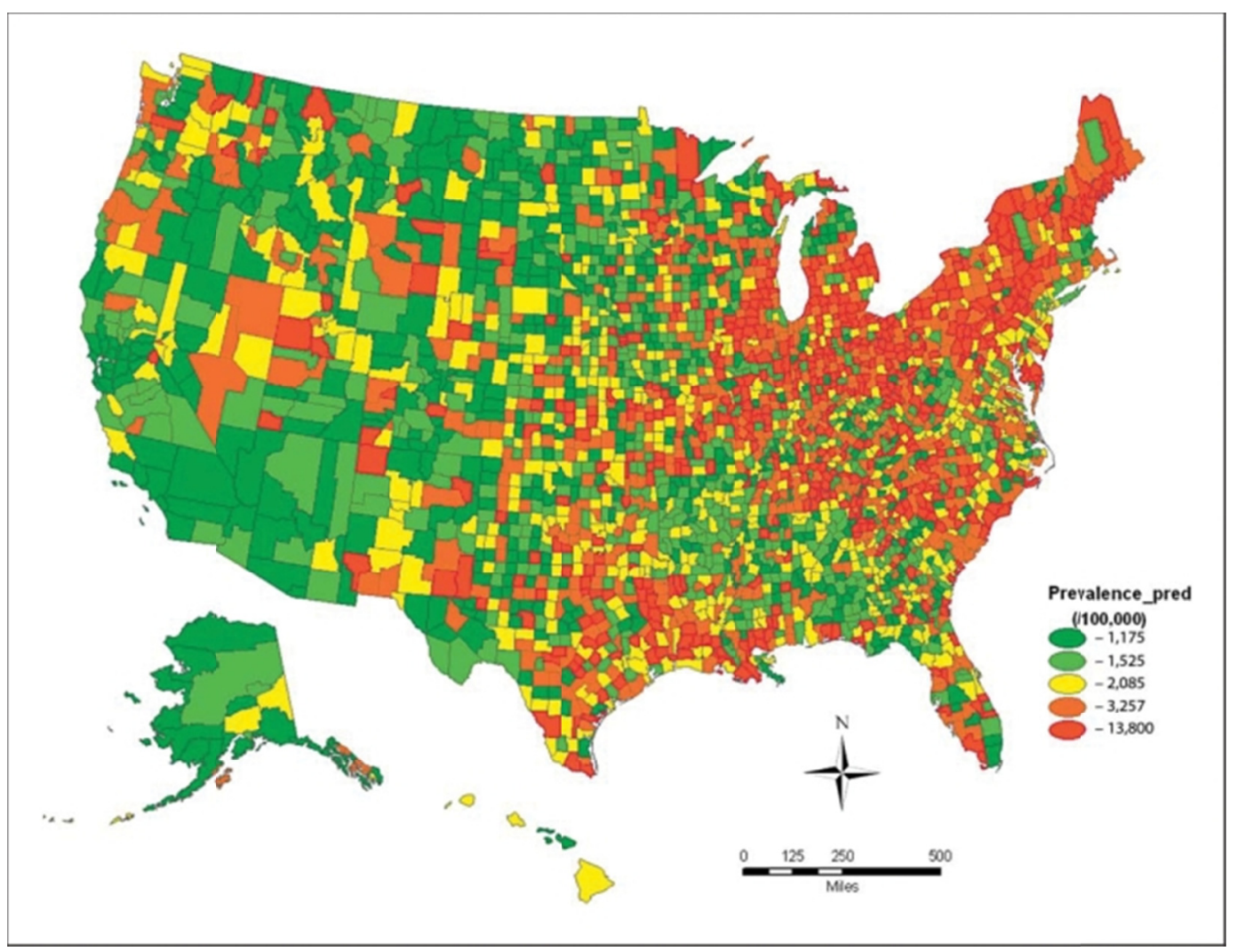

Figure 1. County level-age and race-standardized prevalence (per 100,000) of Parkinson disease among medicare beneficiaries in the United States (year $=2003$ ) (Willis et al., 2010)

\section{Discussion}

The burden of chronic conditions such as PD is projected to grow substantially over the next few decades as the size of the elderly population grows (Mhyre, et al., 2012). In this study, we found that patients with CHF and Parkinson disease are more prevalent in Caucasian males compared to other races. The average age characteristic was 80 years. Hospital admission, decreases with median household income. Patients with low income were admitted more than those with higher income. Patients with Parkinson disease, stayed longer in the hospital than patients without Parkinson. Consequently, the total charge incurred during hospitalization was more in patients with PD. We also, found that patients with PD were discharged more from urban non-teaching hospital than urban teaching hospital. PD compared with non-PD patients had significantly less morbid obesity. Other less significant co-morbidities observed in all patients were diabetes, renal insufficiency, stroke and obstructive sleep apnea. After adjusting for age, gender and race the results showed that morbid obesity did not affect hospital death. However, length of stay and total charge were significantly affected. It is expected that as a patient stays longer in the hospital, the cost of staying will eventually affect total charge. Stroke increased hospital death, length of stay and total charge. Obstructive sleep apnea affected hospital death. Patients with CHF and PD contributed to the length of stay and total charge in urban and rural hospitals.

\section{Conclusion}

Parkinson is a neurodegenerative disorder that affects the elderly. Stroke increased hospital death, length of stay and total charge. Obstructive sleep apnea affected hospital death. All patients with CHF and PD contributed to the length of stay and total charge in urban and rural hospitals. In conclusion, comorbidities to CHF should be factored in to factors that could contribute readmission of CHF patients, within 90 days of discharge and to the high cost of CHF management. These results suggest that recognition, diagnosis and treatment of PD in CHF patients may reduce frequent readmissions, length of stay, total charges and mortality rates in this patient population. 


\section{References}

Chen, P., Kales, H.C., Weintraub, D., Blow, F.C., Jiang, L., Ignacio, R.V., \& Mellow, A.M. (2007). Depression in veterans with Parkinson's disease: frequency, co-morbidity and healthcare utilization. International Journal of Geriatric Psychiatry, 22(6), 543-548. https://doi.org/10.1002/gps.1712

Cruickshank, T.M., Reyes, A.R., \& Ziman, M.R. (2015). A systematic Review and Meta-Analysis of Strength Training in Individuals with Multiple Sclerosis or Parkinson Disease. Medicine, 94(4), 1-15. https://doi.org/10.1097/MD.0000000000000411

Csoti, I., Jost, W.H., \& Reichmann, H. (2016). Parkinson's disease between internal medicine and neurology. Journal of Neural Transmission, 123, 3-17. https://doi.org/10.1007/s00702-015-1443-z

Dorsey, E.R., Constantinescu, R., Thompson J.P., Biglan, K.M., Holloway, R.G., Kieburtz, K., ... Tanner, C.M. (2007). Projected number of people with Parkinson disease in the most populous nations, 2005 through 2030. Neurology, 68, 384-386. https://doi.org/10.1212/01.wnl.0000247740.47667.03

Firoz, C.K., Jabir, N.R., Khan, M.S., Mahmoud, M., Shakil, S., Damanhouri, G.A., ... Kamal, M.A. (2015). An overview on the correlation of neurological disorders with cardiovascular disease. Saudi J Biol Sci., 22(1), 19-23. https://doi.org/10.1016/j.sjbs.2014.09.003

Gorell, J.M., Johnson, C.C., \& Rybicki, B.A. (1994). Parkinson's disease and its comorbid disorders: an analysis of Michigan mortality data, 1970-1990. Neurology, 44, 1865-1868. https://doi.org/10.1212/WNL.44.10.1865

Hall, M.J., DeFrances, C.J., Williams, S.N. et al. (2010). National Hospital Discharge Survey: 2007. National health statistics reports, 29. Hyattsville, MD: National Center for Health Statistics.

Hirtz, D., Thurman, D.J., Gwinn-Hardy, K., Mohamed, M., Chaudhuri, A.R., \& Zalutsky, R. (2007). How common are the "common" neurologic disorders? Neurology, 68, 326-337. https://doi.org/10.1212/01.wnl.0000252807.38124.a3

Hu, G., Jousilahti, P., Nissinen, A., Antikainen, R., Kivipelto, M., \& Tuomilehto, J. (2006). Body mass index and the risk of Parkinson disease. Neurology, 67, 1955-1959. https://doi.org/10.1212/01.wnl.0000247052.18422.e5

Huse, D.M., Schulman, K., Orsini, L., Castelli-Haley, J., Kennedy, S., \& Lenhart, G. (2005). Burden of illness in Parkinson's disease. Mov. Disord, 20, 1449-1454. https://doi.org/10.1002/mds.20609

Leibson, C.L., Maraganore, D.M., Bower, J.H., Ransom, J.E., O’Brien, P.C., \& Rocca, W.A. (2006). Comorbid conditions associated with Parkinson's disease: a population based study. Mov Disord., 21(4), 446-455. https://doi.org/10.1002/mds.20685

Maeda, T., Nagata, K., Satoh, Y., Yamazaki, T., \& Takano, D. (2013). High prevalence of gastroesophageal reflux disease in Parkinson's disease: a questionnaire-based study. Parkinson's disease. https://doi.org/10.1155/2013/742128

Mhyre, T.R., Boyd, J.T., Hamill, R.W., \& Maguire-Zeiss, K.A. (2012). Parkinson's disease. Sub-Cellular Biochemistry, 65, 389-455. https://doi.org/10.1007/978-94-007-5416-4_16

Miyake, Y., Tanaka, K., Fukushima, W., Sasaki, S., Kiyohara, C., Tsuboi, Y., ... Nagai, M. (2010). Fukuoka Kinki Parkinson's Disease Study Group Case-control study of risk of Parkinson's disease in relation to hypertension, hypercholesterolemia, and diabetes in Japan. J Neurol Sci., 293(1-2), 82-86.

Nance, M.A (2012). Therapy in Huntington's disease: where are we? Curr Neurol Neurosci Rep, 12, 359-366. https://doi.org/10.1007/s11910-012-0277-4

Pagano, G., Tan, E.E., Haider, J.M., Bautista, A., \& Tagliati, M. (2014). Constipation is reduced by beta-blockers and increased by dopaminergic medications in Parkinson's disease. Parkinsonism Relat Disord., S1353-8020(14), 435.

Parkinson's UK. (2018). Retrieved February 7, 2018, from https://www.parkinsons.org.uk/news/26-september-2016/new-research-highlights-importance-cardiovascula r-health-parkinsons

Ransmayr, G. (2015). Cognitive impairment in Parkinson's disease. Psychiatria Danubina, 27, 458-461.

Roger, V.L. (2013). Epidemiology of Heart Failure. Circulation Research, 113(6), 646-659. https://doi.org/10.1161/CIRCRESAHA.113.300268 
Sun, Y., Chang, Y.H., Chen, H.F., Su, Y.H., Su, H.F., \& Li, C.Y. (2012). Risk of Parkinson disease onset in patients with diabetes. Diabetes Care., 35(5), 1047-1049. https://doi.org/10.2337/dc11-1511

Swallow, D.M.A., Lawton, M.A., Grosset, K.A., Malek, N., Klein, J., Baig, F., .. Grosset, D.G. (2016). Statins are underused in recent-onset Parkinson's disease with increased vascular risk: findings from the UK Tracking Parkinson's and Oxford Parkinson's disease Centre (OPDC) discovery cohorts. J Neurol Neurosurg Psychiatry, 87, 1183-1190. https://doi.org/10.1136/jnnp-2016-313642

The Statistical Analysis System (SAS) software 9.3 (SAS Institute, Cary, NC) and Statistical Analysis and Graphics (NCSS 9.0.7, Kaysville, UT).

Truong, D.D., Bhidayasiri, R., \& Wolters, E. (2008). Management of non-motor symptoms in advanced Parkinson disease. J Neurol Sci, 266, 216-228. https://doi.org/10.1016/j.jns.2007.08.015

Willis, A.W., Evanoff, B.A., Lian, M., Criswell, S.R., \& Racette, B.A. (2010). Geographic and ethnic variation in Parkinson disease: A population based study of US Medicare Beneficiaries. Neuroepidemiology, 34, 143-151. https://doi.org/10.1159/000275491

Xu, Q., Park, Y., Huang, X., Hollenbeck, A., Blair, A., Schatzkin, A., \& Chen, H. (2011). Diabetes and risk of Parkinson's disease. Diabetes Care, 34(4), 910-915. https://doi.org/10.2337/dc10-1922

Zesiewicz, T.A., Strom, J.A., Borenstein, A.R. et al. (2004). Heart failure in Parkinson's disease: analysis of the United States Medicare current beneficiary survey. Parkinsonism Relat. Disord., 10, 417-420. https://doi.org/10.1016/j.parkreldis.2004.04.001

Zhang, T., Yu, S., Guo, P., Du, Y., Hu, Y., Piao, Y., \& Zhang, W. (2016). Nonmotor symptoms in patients with Parkinson disease: A cross-sectional observational study. Medicine, 95(50), e5400. https://doi.org/10.1097/MD.0000000000005400

\section{Copyrights}

Copyright for this article is retained by the author(s), with first publication rights granted to the journal.

This is an open-access article distributed under the terms and conditions of the Creative Commons Attribution license (http://creativecommons.org/licenses/by/4.0/). 